\title{
THE DEVELOPMENT OF EXPORT POTENTIAL OF SMALLAND MEDIUM ENTERPRENEURSHIP IN THE VOLGOGRAD REGION: PROBLEMS AND SOLUTIONS
}

\author{
Sergey A. Korobov \\ Volgograd State University, Volgograd, Russian Federation
}

\begin{abstract}
The development of export potential of small and medium enterprises of the Volgograd region is important for the economy of the region. In the conditions of sanctions imposed by the United States and the European Union, it is the export business that will allow diversifying incoming and outgoing financial flows and ensuring the highest profitability and cost-effectiveness of production in the region. The article analyzes the general condition of small and medium enterprises in the Volgograd region, the existing measures of state support of business, useful for exporters. The author considers the total export potential of the region, singles out the main problems of export-oriented business in the Volgograd region. Special attention is focused on the Center of export support of the Volgograd region as a key element of the entire infrastructure of support of small and medium-sized enterprises, mainly engaged in foreign trade activities. Building a unified classification approach to sharing the development of export activities of businesses is based on the economic model by O.V. Inshakov, according to which all the resources of the production function of an entrepreneur are classified into informational, institutional, material, human, organizational and technological. The use of the model provides a clear structure of the main stakeholders' resources in the development of export activities of small and medium enterprises: state authorities, Vnesheconombank, the Russian export centre, SME Bank, the Federal Fund for Innovations, the Russian Agency for insurance of export loans and investments etc. In the conclusion the author suggests new directions for the development of export-oriented small and medium business in the Volgograd region. policy.

Key words: region, small and medium enterpreneurship, export potential, development, political system, state
\end{abstract}

УДК 658.114

ББК 65.292

\section{РАЗВИТИЕ ЭКСПОРТНОГО ПОТЕНЦИАЛА МАЛОГО И СРЕДНЕГО ПРЕДПРИНИМАТЕЛЬСТВА ВОЛГОГРАДСКОЙ ОБЛАСТИ: ПРОБЛЕМЫ И РЕШЕНИЯ}

\author{
Сергей Александрович Коробов \\ Волгоградский государственный университет, г. Волгоград, Российская Федерация
}

\begin{abstract}
Аннотация. Развитие экспортного потенциала малого и среднего предпринимательства Волгоградской области имеет важное значение для всей экономики региона. В условиях введения внешних санкций со

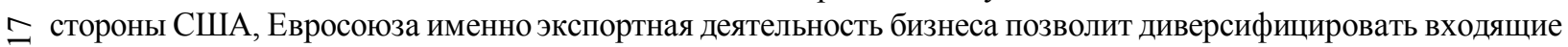
и исходящие финансовые потоки и обеспечить высокую прибыльность и рентабельность производимой в регионе продукции. Первоначально в статье анализируется общее состояние малого и среднего предпринич мательства в Волгоградской области, существующие меры государственной поддержки бизнеса, на которые о̊̆ в том числе могут рассчитывать и экспортеры. Далее рассматривается весь совокупный экспортный потенциал региона, вычленяются основные проблемы экспортно-ориентированного бизнеса Волгоградской области. Особое внимание в статье концентрируется на Центре поддержки экспорта Волгоградской области как (?) ключевом элементе всей инфраструктуры поддержки малого и среднего предпринимательства, преимуще-
\end{abstract}


ственно занятого во внешнеэкономической деятельности. Для выстраивания единого классификационного подхода к разделению ресурсов развития экспортной деятельности бизнеса привлекается экономическая модель О.В. Иншакова, согласно которой все ресурсы производственной функции предпринимателя подразделяются на информационные, институциональные, материальные, человеческие, организационные и технико-технологические. Применение данной модели позволило четко структурировать по ресурсам основных стейкхолдеров развития экспортной деятельности малого и среднего предпринимательства: органы государственного управления, Внешэкономбанк, Российский экспортный центр, МСП банк, Федеральный Фонд содействия инноваций, Российское агентство по страхованию экспортных кредитов и инвестиций и др. В конце статьи предлагаются новые направления развития экспортно-ориентированного малого и среднего бизнеса в Волгоградской области.

Ключевые слова: регион, малое и среднее предпринимательство, экспортный потенциал, развитие, система, государственная политика.

Малое и среднее предпринимательство (далее - МСП) является локомотивом роста национальной экономики. В условиях внешних экономических санкций развитие экспортного потенциала малого и среднего бизнеса становится приоритетной задачей для органов государственного управления на всех уровнях власти [4].

Прежде чем перейти к вопросу развития экспортного потенциала МСП, рассмотрим общую картину состояния МСП Волгоградской области за прошедший период.

В Волгоградской области в 2015 г. в сфере МСП по ряду показателей наблюдалась положительная динамика - увеличилось количество индивидуальных предпринимателей, выросли налоговые поступления по специальным режимам налогообложения. По темпам роста налогов на совокупный доход консолидированного бюджета, уплачиваемых субъектами МСП, среди 85 субъектов РФ Волгоградская область поднялась на 24-е место, улучшив свой результат на 31 пункт (55-е место за аналогичный период 2014 г.), а в Южном федеральном округе среди 6 субъектов РФ заняла 2-е место против 5-го за 9 месяцев 2014 года [2].

В 2016 г. в Волгоградской области осуществляли деятельность 229 средних предприятий, 3035 малых предприятий и более 25000 микропредприятий. По состоянию на 1 января 2017 г. в Волгоградской области зарегистрировано индивидуальных предпринимателей - 60621 (каждый 42-й житель региона), что на 683 единицы больше, чем в 2015 году. В 2016 г. налоги на совокупный доход, поступившие в консолидированный бюджет Волгоградской области, составили 4996,8 млн руб. с темпом роста $112,1 \%$ от- носительно 2015 г. (за 2015 г. - 4 459,2 млн руб.). За 2016 г. по темпам роста налогов на совокупный доход консолидированного бюджета, уплачиваемых субъектами малого и среднего предпринимательства, среди субъектов Российской Федерации Волгоградская область поднялась на 13-е место (21-е место за 2015 г.), а в Южном федеральном округе сохранила 4-е место [2].

Таким образом, за период 2015-2016 гг. в Волгоградской области по ряду показателей, характеризующих состояние МСП, сохраняется положительная динамика.

Положительной динамике способствует в том числе реализация на территории Волгоградской области комплекса мер государственной поддержки МСП, основная задача которых - создание максимально простых и комфортных условий для работы бизнеса в регионе.

На поддержку и развитие МСП в Волгоградской области в 2016 г. было направлено 13,5 млн руб. средств областного бюджета и 158,8 млн руб. субсидий федерального бюджета [8]. Средства областного и федерального бюджетов реализовывались в виде прямой финансовой поддержки субъектов МСП, через организации инфраструктуры предпринимательства и развитие молодежного предпринимательства. В 2016 г. прямая финансовая поддержка в форме субсидий по двум наиболее востребованным и эффективным механизмам (по затратам на лизинг и приобретение оборудования в рамках модернизации) была оказана 133 субъектам МСП на общую сумму 100,0 млн рублей [8]. Получатели субсидий смогли создать новые рабочие места, обеспечить положительную динамику основных экономических показателей деятельности. 
Поддержкой, предоставляемой организациями инфраструктуры поддержки МСП, в 2016 г. воспользовались более 3000 субъектов МСП. Некоммерческим партнерством «Региональный гарантийный фонд» в 2016 г. предоставлено 63 поручительства на сумму 239,4 млн руб. по кредитам субъектов малого и среднего предпринимательства на общую сумму 594,1 млн рублей. Государственным фондом «Региональный микрофинансовый центр» (микрофинансовой организацией) выданы займы 10 микрофинансовым организациям и кредитно-потребительским кооперативам в объеме 118,6 млн руб., которые предоставили микрозаймы 127 субъектам МСП. Государственным автономным учреждением Волгоградской области «Волгоградский областной бизнес-инкубатор» оказана поддержка 29 субъектам малого предпринимательства путем предоставления в аренду нежилых помещений, оборудованных всей необходимой для работы техникой и мебелью, на льготных условиях. Центром инжиниринга, оказывающим поддержку в сфере проектного и технологического инжиниринга, заключено 244 договора на оказание инжиниринговых услуг 174 субъектам МСП. Центром поддержки предпринимательства в 2016 г. организовано и проведено 94 мероприятия для субъектов МСП Волгоградской области, 22 из которых выездные круглые столы в муниципальных образованиях региона [8].

С 2016 г. успешно развивается система взаимодействия органов власти Волгоградской области с акционерным обществом «Корпорация “МСП”». Через сеть многофункциональных центров предприниматели могли получить услуги по подбору по заданным параметрам информации об имуществе, включенном в перечни государственного и муниципального имущества и предназначенного для сдачи в аренду субъектам МСП; об организации участия субъектов предпринимательской деятельности в закупках товаров, работ, услуг; о формах и условиях финансовой поддержки субъектов МСП.

В 2017 г. государственная поддержка МСП направлена на развитие действующих организаций инфраструктуры поддержки предпринимательства: создание на территории области микрофинансовой организации перво- го уровня, многофункциональных центров для бизнеса, центров молодежного инновационного творчества; софинансирование муниципальных программ поддержки МСП моногородов; развитие молодежного предпринимательства. На все эти виды государственной поддержки могут рассчитывать в том числе и экспортно-ориентированные субъекты МСП [2].

Рассмотрим экспортный потенциал Волгоградской области.

Внешнеторговый оборот Волгоградской области в 2016 г. составил 1986 млн долл. США. На долю предприятий Волгоградской области в товарообороте Южного федерального округа в 2016 г. пришлось $10 \%$ стоимости товарооборота (2015 г. - 13,3 \%). Экспорт региона составил 1316 млн долл. США, импорт - 670 млн долл. США [1].

Волгоградская область осуществляла внешнеэкономические связи со 121 страной. В число стран - основных торговых партнеров входят: Казахстан - 11,2 \%, Украина $10,5 \%$, Беларусь - $7 \%$, Германия $-6,8 \%$, Турция - 5,3 \%, Китай - 4,9\%, Франция $4,4 \%[1]$.

В сложившихся неблагоприятных геополитических и экономических условиях, связанных с расширением взаимных внешнеторговых санкций, сохранением низких мировых цен на нефть, энергоносители, черные металлы, зерновые культуры, нестабильностью курса рубля к мировым валютам, сокращение внешнеторгового оборота Волгоградской области в 2016 г. составило около $36 \%$ [1].

Выделяются следующие основные проблемы экспортно-ориентированного бизнеса Волгоградской области:

- сокращение рынков сбыта экспортной продукции волгоградских предприятий в связи с санкционной политикой США и ЕС;

- приостановление действия договора с Украиной о зоне свободной торговли и задержки с поэтапной отменой российских внешнеторговых санкций в отношении Турции.

Ключевой инфраструктурной организацией, которая напрямую несет ответственность за развитие экспортного потенциала малого и среднего предпринимательства Волгоградской области, является Центр поддержки экспорта Волгоградской области, который был создан в июне 2016 г. как структурное под- 


\section{МАКРОЭКОНОМИЧЕСКИЕ И ИНСТИТУЦИОНАЛЬНЫЕ УСЛОВИЯ}

разделение государственного автономного учреждения «Волгоградский областной бизнесинкубатор» [14].

Основными задачами Центра поддержки экспорта Волгоградской области являются:

- содействие выходу субъектов малого и среднего предпринимательства на иностранные рынки товаров, услуг и технологий;

- стимулирование и вовлечение субъектов малого и среднего предпринимательства в экспортную деятельность;

- содействие повышению конкурентоспособности и эффективности деятельности экспортно-ориентированных субъектов малого и среднего предпринимательства.

В рамках своей работы Центр поддержки экспорта Волгоградской области осуществляет следующие виды деятельности:

1. Информационная поддержка участников ВЭД:

- продвижение информации о предприятиях области на российских и зарубежных интернет-ресурсах;

- помощь в установлении контактов с зарубежными бизнес-ассоциациями, поиск деловых партнеров и иностранных инвесторов для предприятий области;

- издание и рассылка презентационных материалов об экспортерах Волгоградской области (в печатном и электронном виде);

- подготовка справок и обзоров зарубежных рынков сбыта, а также обзоров проводимых за рубежом деловых мероприятий;

- проведение семинаров по актуальным вопросам ведения внешнеэкономической деятельности;

- содействие в проведении маркетинговых исследований МСП Волгоградской области.

2. Консультационная поддержка участников внешнеэкономической деятельности:

- предоставление консультаций по вопросам внешнеэкономической деятельности, в том числе посредством привлечения сторонних экспертов;

- подготовка и экспертиза документов для создания предприятий с иностранными инвестициями, зарубежных филиалов предприятий;

- услуги по переводу с иностранных языков и на иностранные языки деловых писем, коммерческих и юридических документов, рекламно-информационных материалов, научно-технических текстов, товарно-сопроводительной документации.

3. Организация встреч и переговоров с иностранными партнерами:

- организация «деловых миссий»-коллективных поездок предпринимательской области для переговоров с иностранными партнерами;

- организация участия предприятий Волгоградской области в международных конгрессно-выставочных мероприятиях;

- организация вебинаров, круглых столов, конференций, форумов, семинаров, мастерклассов и иных публичных мероприятий по тематике экспортной деятельности для субъектов малого и среднего предпринимательства.

В 2016 г. Центром поддержки экспорта Волгоградской области было организовано 8 образовательных сессий, обучение прошли представители из 45 волгоградских компаний [2].

В отличие от Центра поддержки экспорта Волгоградской области, который существует благодаря бюджетной поддержке, Волгоградская торгово-промышленная палата оказывает свои услуги на коммерческой основе:

- организация деловых поездок в регионы России, страны ближнего и дальнего зарубежья;

- организация деловых поездок за рубеж;

- поиск партнеров и оборудования за рубежом;

- прием бизнес-делегаций, организация переговоров по интересам;

- проведение презентаций продукции и услуг предприятий в Волгограде, в регионах России и за рубежом;

- проверка благонадежности иностранных деловых партнеров [13].

Для рассмотрения ключевых ресурсов развития экспортно-ориентированной деятельности МСП Волгоградской области воспользуемся экономической моделью О.В. Иншакова, согласно которой все ресурсы производственной функции предпринимателя подразделяются на информационные, институциональные, материальные, человеческие, организационные и технико-технологические [3]. 
Обозначим ключевые меры экономической поддержки экспортно-ориентированного малого и среднего предпринимательства согласно данной классификации.

\section{I. Информационные ресурсы.}

По линии Минэкономразвития РФ можно выделить информационное мероприятие, связанное с разработкой «паспортов» внешнеэкономических проектов на основании предложений предприятий, для последующего содействия развитию внешнеэкономической деятельности предприятия через торгпредства. Данный вид государственной поддержки осуществляется в следующей последовательности действий:

1. Подготовка «Паспорта» внешнеэкономического проекта предприятия (паспорт проекта; заполненная анкета (информационная карта компании); презентации на русском и английском языках; коды на продукцию; сертификаты на продукцию; письма-обращения руководства предприятия к потенциальным иностранным партнерам).

2. Рассмотрение Паспорта в Администрации Волгоградской области и передача его при положительной экспертизе в Минэкономразвития РФ.

3. Утверждение в Минэкономразвития РФ и передача «паспортов» в Торгпредства РФ.

4. Поиск партнеров Торгпредствами РФ за рубежом [2].

Минпромторгом РФ учреждена автономная некоммерческая организация «Информационно-аналитический центр по вопросам внешнеторговой деятельности», задачами которой являются:

- сбор и анализ информации о регулировании внешней торговли в иностранных государствах, представляющих интерес для российских экспортеров;

- сбор информации о проблемах российских промышленных компаний в области внешней торговли и подготовка рекомендаций по корректировке торговой политики и нормативной правовой базы;

- формирование комплексных решений в области таможенно-тарифного, нетарифного регулирования, защитных мер, а также мер государственной поддержки промышленных предприятий;

- сбор информации по кооперационному потенциалу в промышленном секторе ЕЭП;
- информационная поддержка экспортоориентированных промышленных компаний;

- получениезаключений и консультационной поддержки независимых экспертов по вопросам о средствах правовой защиты, которые могут быть использованы российскими промышленными организациями и Российской Федерацией в интересах национального бизнеса [1] .

\section{II. Человеческие ресурсы.}

Для развития человеческих ресурсов, по нашему мнению, более всего подходит образовательный проект Российского экспортного иентра, в рамках которого проходят курсы повышения квалификации региональных представителей малого и среднего бизнеса, заинтересованных в развитии экспортного потенциала своего предприятия [7].

\section{III. Институциональные ресурсы.}

Установлена нулевая процентная налоговая ставка НДС (ст. 164, 165 Налогового кодекса Российской Федерации) при реализации товаров, вывезенных в таможенной процедуре экспорта, а также товаров, помещенных под таможенную процедуру свободной таможенной зоны; услуг по международной перевозке товаров [6].

В рамках таможенного законодательства можно выделить новые инструменты законодательного регулирования экспортной деятельности: электронное таможенное декларирование, автоматическая регистрация декларации, механизм «единого окна» при совершении таможенных операций, возможность удаленной уплаты таможенных платежей, применение специальных, антидемпинговых и компенсационных пошлин [12].

IV. Материальные (финансовые) ресурсы.

Минпромторг России осуществляет следующие меры прямой финансовой поддержки:

- компенсация затрат на регистрацию объектов интеллектуальной собственности за рубежом;

- компенсация затрат на сертификацию;

- компенсация части затрат на транспортировку продукции;

- компенсация затрат, связанных с участием в выставочно-ярмарочных мероприятиях [1].

Финансовая поддержка экспорта Внешним экономическим банком (ВЭБ) осуществляется по двум направлениям: 


\section{МАКРОЭКОНОМИЧЕСКИЕ И ИНСТИТУЦИОНАЛЬНЫЕ УСЛОВИЯ}

- льготное кредитование по сниженным процентным ставкам (экспортные кредиты иностранным покупателям российских товаров, работ, услуг на цели приобретения продукции; кредиты российским экспортерам в целях покрытия расходов на производство продукции для последующего экспорта (предэкспортное кредитование));

- гарантийная поддержка (гарантии возврата аванса; гарантии надлежащего исполнения; тендерные гарантии; гарантии платежа; гарантии в форме аккредитива; контргарантии в обеспечение любых видов прямых гарантий других банков возврата аванса, надлежащего исполнения, тендерных и др.; гарантии возврата возмещенного НДС, гарантия в пользу таможни) [9].

Банк МСП предоставляет экспортерам кредитные продукты, предполагающие финансирование в сумме до 150 млн руб. сроком от 1 до 5 лет по ставке от 11,5 до 15,5 \% годовых [5].

Через Федеральный Фонд содействия инноваций проходят конкурсы: «Международные программы» (поддержка развитых предприятий, уставами которых предусмотрено проведение научных работ), «Экспорт» (поддержка развитых предприятий, которые имеют опыт продаж наукоемкой продукции за рубежом и нуждаются в проведении дополнительных НИОКР). Финансирование проектов осуществляется в объеме до 15,0 млн руб., при условии 50 \%-го софинансирования из внебюджетных средств [11].

Российское агентство по страхованию экспортных кредитов и инвестиичий осуществляет страхование кредита поставщика и покупателя, подтвержденного аккредитива, гарантий, экспортного факторинга [10].

\section{V. Организационные ресурсы.}

Организационные ресурсы предоставляются практически всеми организациями, ответственными за развитие экономики экспорта. В качестве примера можно привести $\mathrm{Muн-}$ промторг РФ, который осуществляет организацию коллективных выставочно-ярмарочных стендов отечественных товаров в Российской Федерации и за рубежом, постоянно действующих экспозиций. Также на регулярной основе проводятся бизнес-миссии, которые помогают российским экспортерам развивать деловые связи за рубежом.
VI. Технико-технологические ресурсы.

Минпромторгом РФ утвержден перечень технологического оборудования, ввоз которого на территорию РФ не подлежит обложению НДС (более 200 наименований оборудования) [1].

Таким образом, субъектам МСП, планирующим или осуществляющим экспортную деятельность по несырьевым товарам, доступны все необходимые ресурсы для развития собственного бизнеса.

В заключении нами предлагаются следующие направления развития экспортно-ориентированного малого и среднего бизнеса Волгоградской области:

1. В регионе необходимо создать единый Совет по развитию экспортной деятельности предприятий при Губернаторе Волгоградской области. В Совет должны войти представители Комитета экономической политики и развития Администрации Волгоградской области (далее - ABO), Комитета промышленности и торговли $\mathrm{ABO}$, Комитета сельского хозяйства $\mathrm{ABO}$, федеральных ведомств (Управление федеральной налоговой службы, Федеральная таможенная служба), банков (Внешэкономбанк, МСП банк, Росэкимбанк), Российского экспортного центра, Российского агентства по страхованию экспортных кредитов и инвестиций.

2. В рамках Совета разработать и утвердить отраслевые экспортные стратегии по промышленности, сельскому хозяйству и др.

3. В регионе активно создавать новые и развивать текущие организации инфраструктуры поддержки несырьевого экспорта. В каждом муниципальном районе образовывать центры консультационной поддержки экспортеров, экспортно-ориентированные оптово-распределительные центры.

4. Совместно с представителями федеральных органов государственной власти осуществлять развитие регуляторной среды для безбарьерного осуществления несырьевого экспорта Волгоградской области.

5. Развивать меры финансовой и нефинансовой поддержки экспорта, в том числе по региональным государственным программам.

Только при условии единой интеграции усилий всех стейкхолдеров произойдет значительное увеличение объемов экспорта высо- 
котехнологичной продукции региона, будет обеспечен устойчивый рост экспортной составляющей сбыта малого и среднего бизнеса Волгоградской области, создана развитая экспортно-сбытовая сеть и расширена география экспорта.

\section{СПИСОК ЛИТЕРАТУРЫ}

1. Внешнеторговая деятельность промышленных предприятий региона // Портал Комитета промышленности и торговли Волгоградской области. - Электрон. текстовые дан. - Режим доступа: http://promtorg.volgograd.ru/current-activity/ promyshlennost/foreign-economic-activity/, свободный. - Загл. с экрана.

2. Ежегодный отчет о деятельности комитета экономической политики и развития Волгоградской области перед жителями Волгоградской области // Портал Комитета экономической политики и развития Волгоградской области. - Электрон. текстовые дан. - Режим доступа: http://economics. volgograd.ru/current-activity/, свободный. - Загл. с экрана.

3. Иншаков, О. В. «Ядро развития» в контексте новой теории факторов производства / О. В. Иншаков // Экономическая наука современной России. -2003. - № 1. - С. 11-25.

4. Коробов, С. А. Формирование векторов государственной поддержки субъектов малого и среднего предпринимательства (на примере Волгоградской области) / С. А. Коробов, С. И. Фомина // Вестник Волгоградского государственного университета. Серия 3, Экономика. Экология. - 2011. - № 1.C. 31-39.

5. Кредитная поддержка. Портал МСП банка. - Электрон. текстовые дан. - Режим доступа: https://www.mspbank.ru/Predprinimatelyam/directcredit/, свободный. - Загл. с экрана.

6. Налоговый кодекс Российской Федерации. - Доступ из справ.-правовой системы «КонсультантПлюс».

7. Образовательные услуги РЭЦ // Портал Российского экспортного центра. - Электрон. текстовые дан. - Режим доступа: https://www. exportcenter. ru/services/obrazovatelnye-uslugi, свободный. - Загл. с экрана.

8. Отчеты по финансовой поддержке. Федеральный портал малого и среднего предпринимательства. - Электрон. текстовые дан. - Режим доступа: http://smb.gov.ru/ statistics/navy/report/, свободный. - Загл. с экрана.

9. Поддержка экспорта // Портал Внешэкономбанка. - Электрон. текстовые дан. - Режим доступа: http://veb.ru/, свободный. - Загл. с экрана.
10. Поддержка экспорта // Портал Российского агентства по страхованию экспортных кредитов и инвестиций. - Электрон. текстовые дан. - Режим доступа: https://www.exiar.ru/export_support/ financial_support/Insurance_support_EXIAR, свободный. - Загл. с экрана.

11. Программы // Портал Фонда содействия инновациям. - Электрон. текстовые дан. - Режим доступа: http://www.fasie.ru/programs/, свободный. - Загл. с экрана.

12. Таможенный кодекс Российской Федерации. - Доступ из справ.-правовой системы «КонсультантПлюс».

13. Услуги ВТПП // Портал Волгоградской торгово-промышленной палаты. - Электрон. текстовые дан. - Режим доступа: http://volgogradcci.ru/, свободный. - Загл. с экрана.

14. Центр поддержки экспорта Волгоградской области // Портал Волгоградского областного бизнесинкубатора. - Электрон. текстовые дан. - Режим доступа: http://vinkub.ru/, свободный. - Загл. с экрана.

\section{REFERENCES}

1. Vneshnetorgovaya deyatelnost promyshlennykh predpriyatiy regiona [Foreign Trade Activity of the Industrial Enterprises of the Region]. Portal Komiteta promyshlennosti $i$ torgovli Volgogradskoy oblasti [Portal of the Committee for Industry and Trade of the Volgograd Region]. URL: http://promtorg.volgograd.ru/ current-activity/promyshlennost/foreign-economicactivity/.

2. Ezhegodnyy otchet o deyatelnosti komiteta ekonomicheskoy politiki i razvitiya Volgogradskoy oblasti pered zhitelyami Volgogradskoy oblasti [Annual Report on the Activities of the Committee for Economic Policy and Development of the Volgograd Region to the Residents of the Volgograd Region]. Portal Komiteta ekonomicheskoy politiki i razvitiya Volgogradskoy oblasti [Portal of the Committee for Economic Policy and Development of the Volgograd Region]. URL: http://economics.volgograd.ru/currentactivity/.

3. Inshakov O.V. «Yadro razvitiya» v kontekste novoy teorii faktorov proizvodstva ["The Development Core" in the Context of the New Theory of Production Factors]. Ekonomicheskaya nauka sovremennoy Rossii, 2003, no. 1, pp. 11-25.

4. Korobov S.A., Fomina S.I. Formirovanie vektorov gosudarstvennoy podderzhki subyektov malogo i srednego predprinimatelstva (na primere Volgogradskoy oblasti) [Formation of Vectors of State Support for Small and Medium-Sized Business (Case of the Volgograd Region)]. Vestnik Volgogradskogo gosudarstvennogo universiteta. Seriya 3, Ekonomika. 


\section{МАКРОЭКОНОМИЧЕСКИЕ И ИНСТИТУЦИОНАЛЬНЫЕ УСЛОВИЯ}

Ekologiya [Science Journal of Volgograd State University. Global Economic System], 2011, no. 1, pp. 31-39.

5. Kreditnaya podderzhka. Portal MSP banka [Credit Support. Portal of SME Bank]. URL: https:// www.mspbank.ru/Predprinimatelyam/direct-credit/.

6. Nalogovyy kodeks Rossiyskoy Federatsii [Tax Code of the Russian Federation]. Access from Reference Legal System "KonsultantPlyus".

7. Obrazovatelnye uslugi RETs [Educational Services of REC]. Portal Rossiyskogo eksportnogo tsentra [Portal of Russian Export Center]. URL: https:// Www.exportcenter.ru/services/obrazovatelnyeuslugi.

8. Otchety pofinansovoy podderzhke. Federalnyy portal malogo i srednego predprinimatelstva [Reports on the Financial Support. Federal Portal for Small and Medium-Sized Enterprises]. URL: http://smb.gov.ru/ statistics/navy/report.

9. Podderzhka eksporta [Export support]. Portal Vneshekonombanka [Portal of Vneshekonombank]. URL: http://veb.ru.
10. Podderzhka eksporta [Export support]. Portal Rossiyskogo agentstva po strakhovaniyu eksportnykh kreditov $i$ investitsiy [Portal of the Russian Agency for Insurance of Export Credits and Investments]. URL: https://www.exiar.ru/export_support/financial_support/ Insurance_support_EXIAR/.

11. Programmy [Programs]. Portal Fonda sodeystviya innovatsiyam [Portal of Innovation Promotion Foundation]. URL: http://www.fasie.ru/ programs.

12. Tamozhennyy kodeks Rossiyskoy Federatsii [Customs Code of the Russian Federation]. Access from Reference Legal System "KonsultantPlyus".

13. Uslugi VTPP [VCCI Services]. Portal Volgogradskoy torgovo-promyshlennoy palaty [Portal of the Volgograd Chamber of Commerce and Industry]. URL: http://volgogradcci.ru/.

14. Tsentr podderzhki eksporta Volgogradskoy oblasti [The Export Support Center of the Volgograd region]. Portal Volgogradskogo oblastnogo biznesinkubatora [Portal of the Volgograd Regional Business Incubator]. URL: http://vinkub.ru/.

\section{Information about the Author}

Sergey A. Korobov, Candidate of Sciences (Economics), Acting Head of Department of Management, Volgograd State University, Prosp. Universitetsky, 100, 400062 Volgograd, Russian Federation, korobovfamily@mail.ru, econmanag@volsu.ru.

\section{Информация об авторе}

Сергей Александрович Коробов, кандидат экономических наук, и.о. заведующего кафедрой менеджмента, Волгоградский государственный университет, просп. Университетский, 100, 400062 г. Волгоград, Российская Федерация, korobovfamily@mail.ru, econmanag@volsu.ru. 